\title{
Effect of Uniaxial Stress on Bursting Energy Absorption of Paper
}

\author{
Konrad Olejnik, ${ }^{\mathrm{a}, *}$ Anna Stanisławska, ${ }^{\mathrm{a}}$ and Jean-Francis Bloch ${ }^{\mathrm{b}}$ \\ The overall usefulness of the bursting energy absorption (BEA) was \\ studied for a better analysis of paper strength properties. Additionally, the \\ changes of the BEA during more complex deformations of paper products, \\ e.g., preliminary or simultaneous tensile and burst, were determined. For \\ the purpose of the research, an experimental setup was designed. The \\ results showed that the correlation between BEA and bursting strength \\ was linear, but the proportionality strongly depended on paper grade. \\ Thus, a more accurate method to characterize the bursting resistance \\ (BR) of paper was proposed. The BR parameter is described by the three \\ following parameters: average bursting strength, average bursting energy \\ absorption, and the slope of the fitted linear regression curve (relationship \\ between the bursting energy absorption and the bursting strength). This \\ method revealed new mechanical behaviors of papers related to their \\ preloading.
}

Keywords: Paper; Mechanical properties; Fracture; Bursting strength; Bursting energy absorption; BEA

Contact information: a: Centre of Papermaking and Printing, Lodz University of Technology, Wolczanska 221, 93-005 Lodz, Poland; b: 3SR, Univ. Grenoble Alpes, CNRS, Grenoble INP, Institute of Engineering, France; *Corresponding author: konrad.olejnik@p.lodz.pl

\section{INTRODUCTION}

Paper products are often subjected to different mechanical forces and dimensional changes such as stretching, compression and crushing, puncture, burst, cracking, tearing, bending, fracture, twisting, or torsion. Resistance to these deformations determines the performance of paper products. It is common that more than one type of deformation occurs simultaneously. The mechanical properties of paper depend on many factors, e.g., the nature of raw-materials and their morphology, fiber distribution within the paper structure (orientation, formation), strength of inter-fiber bonds and bonded area in paper, directions of stress and deformation, and external conditions viz. ambient temperature and humidity (Böhmer 1962; Stenitzer 1967; El-Hosseiny and Anderson 1999; Borch et al. 2002; Szewczyk and Tarnawski 2004). The general resistance of the material to mechanical impact can be described as its ability to absorb energy of deformation. In papermaking, tensile energy absorption (TEA) is the most popular parameter. However, it does not give full information on the capability of paper to absorb energy, as it refers only to loads applied in-plane.

Since the invention of Mullen burst tester in 1887, the bursting strength of paper and paperboard remains one of the most important out-of-plane strength properties. It is defined as a measure of the force required to rupture the face of paper or board. It reflects the complex process of deformation of the paper structure. The complexity of this parameter is a consequence of the shape of diaphragm being deformed during the test and the multi-axial forces exerted on the paper structure. As a result, the resistance of paper in 
this test depends simultaneously on its tensile strength and elongation. However, for industrially produced papers, the elongation is the main factor that limits bursting strength due to the anisotropy of the paper extensibility. The elongation in the machine direction (MD) is usually lower than that in cross direction (CD). During the burst test, paper is stretched uniformly in all directions and the failure therefore commonly occurs across the MD (Fig. 1). Therefore, it would be advantageous to increase the elongation of the paper in the MD direction. Bursting strength is proportional to the arithmetic mean of CD and MD tensile strength and the square root of strain measured in MD (Borch et al. 2002).

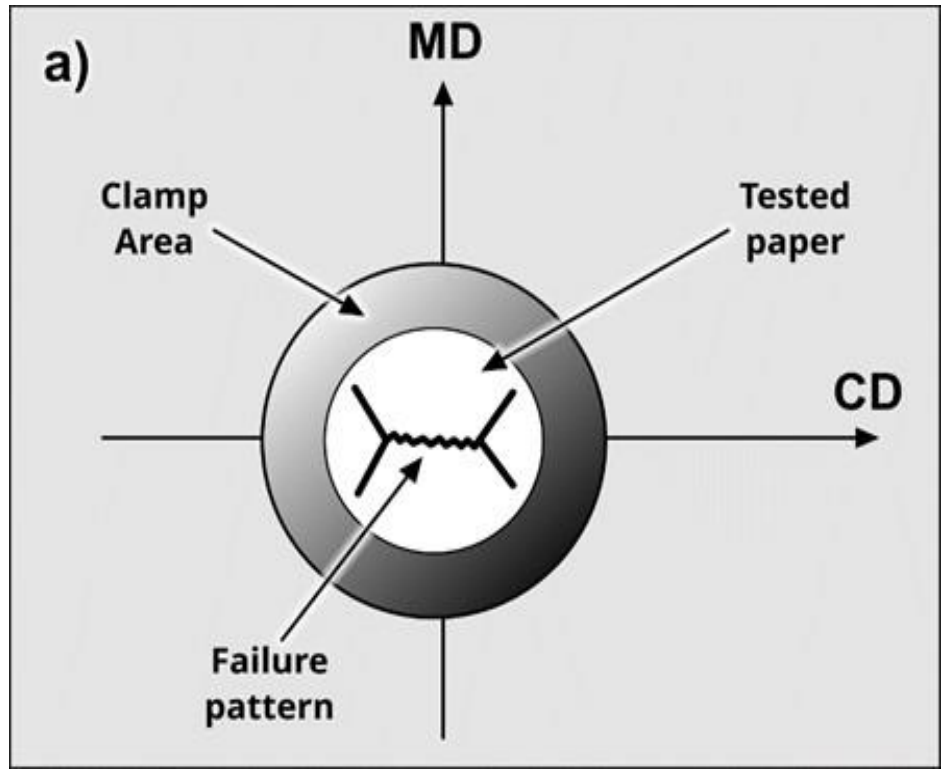

Fig. 1. Typical failure pattern during the paper bursting strength test

The first mathematical attempts to describe the Mullen apparatus operation and the burst test itself were undertaken by Carson and Worthington (1931) and Davis and Edwards (1936). Detailed analyses of this phenomenon carried out by Böhmer (1962) and Stenitzer (1967) illustrated a more precise relationship (Eq. 1),

$$
P_{M A X-T}=\sqrt{6} \frac{h}{r}\left(\sigma_{M D}+\sigma_{C D} \sqrt{\frac{\varepsilon_{M D}}{\varepsilon_{C D}}}\right) \sqrt{\varepsilon_{M D}}
$$

where $P_{M A X-T}$ is the theoretical, maximum bursting pressure, $h$ is the thickness of the sheet, $r$ is the radius of the testing area (circular boundary of the clamp), $\sigma$ is the stress, $\varepsilon$ is the strain, MD is the machine direction, and CD is the cross direction.

Bursting pressure is related to the strain at rupture and also depends on the stiffness and lateral contraction in MD and CD (Borch et al. 2002). Stresses are not uniformly distributed within the sample structure. The highest value of stress is located at the center of test piece and it decreases as the periphery is approached. Taking into account the general heterogeneity of the paper structure, the energy absorption is also not uniform (Gander et al. 1967; Whitsitt 1972a,b,c). While the fact significance and usefulness of this measurement is debatable, it reflects a possible situation that may happen during the use of paper. The value of the bursting pressure increases with increasing basis weight of paper and degree of pulp refining (El-Hosseiny and Anderson 1999; Borch et al. 2002). Bursting strength shows a composite image of toughness, tensile, elongation, and shear 
characteristics. In some cases, therefore, it can be more useful than tensile tests (Böhmer 1962; Borch et al. 2002). Moreover, the test is easy to run and very quick, and above all, it correlates well with final product strength performance.

Several factors affect the burst test result, including clamping strength, elasticity of diaphragm, test speed, sensor calibration, and platen condition (Whitsitt 1972a,b,c; Strikwerda and Considine 1991). Some of these (e.g., elasticity of diaphragm, test speed) are defined in standards, but others often depend on technology used by a given producer or by an adjustment of the device (e.g., clamping strength). Nevertheless, a method for measuring the bursting strength has been accepted as a standard for paper and board by most recognized standardization organizations (e.g., ISO, TAPPI, ASTM). Furthermore, based on the kinetics of both hydraulic pressure and volume acting on the test piece during measurement, bursting energy absorption (BEA) can be calculated. Similarly, to the commonly used tensile energy absorption (TEA) parameter, the BEA characterizes the ability of a material to absorb energy. BEA is defined as the amount of energy per unit surface area of a test piece when it is stretched to rupture, expressed in $\mathrm{J}^{-2}{ }^{-2}$ (Eq. 2),

$$
B E A=\frac{1}{A} \int_{0}^{V_{M A X}}(P d V)
$$

where BEA is the bursting energy absorption, $V_{\mathrm{MAX}}$ is the maximum bursting volume acting on the tested sample when it is stretched to rupture, $P$ is the bursting pressure, $V$ is the bursting volume acting on the tested sample at a given bursting pressure $P$, and $A$ is the testing area of the paper.

BEA is especially important for packaging papers as it is directly related to a paper's ability to withstand external and/or internal forces and thus to protect a product during shipment. Despite its importance, the energy absorption during burst testing has been described in few publications (Gander et al. 1967). This significance and the lack of thorough scientific analysis of the subject were the motivations for undertaking research in this area.

The main objective of the presented research was to evaluate the overall usefulness of the BEA parameter for a better analysis of paper strength properties. For example, one question was whether BEA is proportional to bursting pressure. If indeed such a proportionality can be demonstrated, then the next question arises as to whether this proportionality is the same for all papers. An affirmative answer would mean that the BEA parameter would not be of great cognitive importance. The second aim was to determine the changes of the BEA during more complex deformations of paper products, e.g., simultaneous tensile and burst.

\section{EXPERIMENTAL}

Commercial papers were used. Their properties are presented in Table 1. Paper samples were conditioned according to ISO 187 (1990). Tests were carried out in the standard conditioning. The following properties were determined in accordance with ISO standards: basis weight (ISO 536 2019), thickness and apparent density (ISO 534 2011), tensile index and elongation (ISO 1924-2 2008), bursting strength and burst index (ISO 2758 2014). 
Table 1. Basic Characteristics of the Papers Used in the Research

\begin{tabular}{|c|c|c|c|}
\hline Paper Type & $\begin{array}{c}\text { Basis Weight } \\
\left(\mathrm{g} / \mathrm{m}^{2}\right)\end{array}$ & $\begin{array}{c}\text { Thickness } \\
(\mu \mathrm{m})\end{array}$ & $\begin{array}{c}\text { Apparent Density } \\
\left(\mathrm{g} / \mathrm{cm}^{3}\right)\end{array}$ \\
\hline Clupak & 70 & 108 & 0.648 \\
\hline Liner & 90 & 137 & 0.656 \\
\hline Natron kraft & 35 & 58 & 0.601 \\
\hline Offset & 100 & 106 & 0.945 \\
\hline Bulky & 80 & 180 & 0.446 \\
\hline Map paper & 93 & 108 & 0.861 \\
\hline Fluting & 83 & 125 & 0.664 \\
\hline Whatman blotting paper & 265 & 453 & 0.585 \\
\hline
\end{tabular}

To quantify the BEA, determinations of the changes in both diaphragm volume and pressure during the burst test were required. For the purpose of this research, the experimental setup was prepared (Fig. 2). Bursting strength was measured using the standard Mullen burst tester (App. 4, Type 2-4, Lorentzen \& Wettre, Kista, Sweden). The analog pressure gauge was replaced with a high-quality pressure transmitter type 511 (Huba Control, Würenlos, Switzerland). This transmitter was connected to a computer via an interface that enabled data sampling from the pressure gauge at a frequency of $1 \mathrm{kHz}$. For simultaneous tensile and burst experiments (BEA during simultaneous tensile of the sample), the Mullen device was equipped with special clamps and weight hanger to apply a given load in CD or MD during the test. In the presented setup, a paper specimen (total length: $360 \mathrm{~mm}$, width: $60 \mathrm{~mm}$ ) was clipped between the clamps. The distance between clamps was $270 \mathrm{~mm}$. One clamp was attached to the weight hanger. Different weights were prepared and used for the tests. The burst test for under load experiments was conducted immediately after the sample was subjected to a given tensile load.

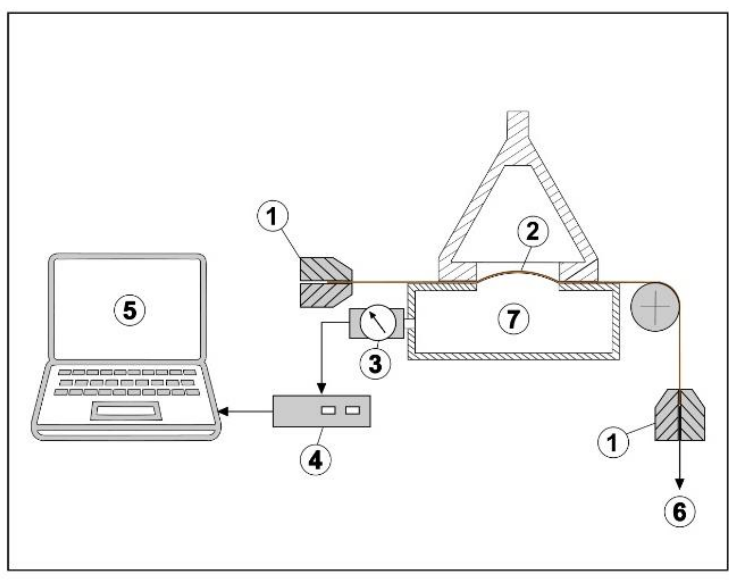

a)

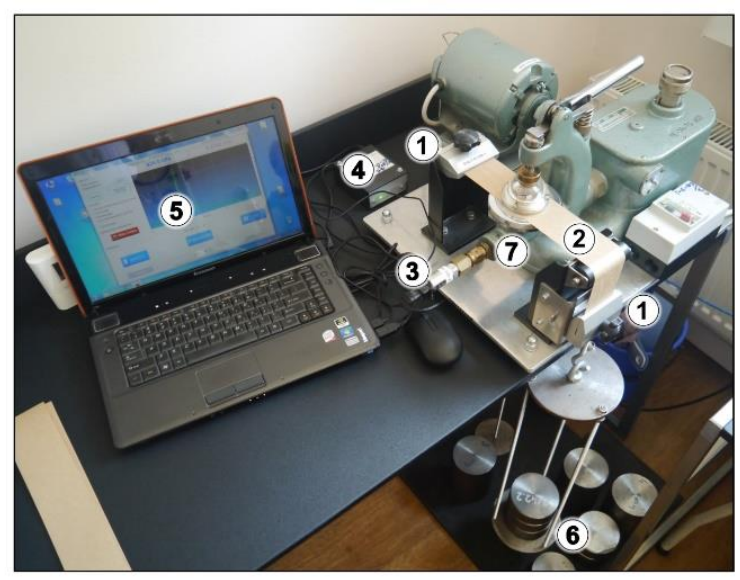

b)

Fig. 2. The experimental setup for burst tests: a) Schematic and b) Experimental setup 1 - clamps, 2 - tested sample, 3 - pressure sensor, 4 - data transfer interface, 5 - computer, 6 weight hanger, 7 - pressure chamber in Mullen device

The bursting energy absorption was determined for three different cases:

a) standard test - tested sample was not subjected to any additional stresses,

b) BEA after pre-load - tested sample was pre-deformed in $\mathrm{CD}$ or $\mathrm{MD}$ and subsequently tested in Mullen tester, 
c) BEA under load - tested sample was simultaneously subjected to tensile load in CD or MD and tested in Mullen tester.

The BEA is the total work done per unit area of a paper stretched to rupture and is calculated as the area under the bursting pressure-bursting volume curve related to the sample circular area subjected to deformation.

Because BEA is calculated as the area (under the curve) divided by the sample area (i.e., the area of the opening in the burst tester), it is expressed in $\mathrm{J}^{-\mathrm{m}^{-2}}$. BEA is the measure of the amount of energy that can be absorbed by a paper of a unit area.

The investigated papers differed in basis weight, so it was interesting to compare how much energy can be absorbed by the same mass $(e . g ., 1 \mathrm{~g})$ of each material. This data could provide information on paper structure capability to absorb energy. For this purpose, BEA index was calculated as bursting energy absorption of paper, in $\mathrm{J}^{-\mathrm{m}^{-2}}$, divided by the basis weight of paper, in $\mathrm{g} . \mathrm{m}^{-2}$. Accordingly, the BEA index is expressed in $\mathrm{J}_{\mathrm{g}} \mathrm{g}^{-1}$.

During pre-deformation, the papers were strained at a constant elongation rate of $20 \mathrm{~mm} / \mathrm{min}$ until the targeted tensile load was obtained. The Instron model 5545 tensile testing machine controlled by Bluehill 2 testing software (Instron ${ }^{\circledR}$, High Wycombe, UK) was used for sample pre-deformation and for determination of tensile properties. After the target load was reached, the paper sample was transferred to the Mullen tester. The time between the end of the preload (Instron) and the start of the burst test (Mullen) was not more than 10 seconds. Sample dimensions for Instron pre-deformation were the same as those for modified Mullen testing $(270 \mathrm{~mm}$ x $60 \mathrm{~mm})$. At least 20 measurements were carried out for a given paper during a given experiment. The average value, standard deviation, and coefficient of variation were calculated.

\section{RESULTS AND DISCUSSION}

Typical pressure curves for burst tests for packaging papers are shown in Fig. 3.

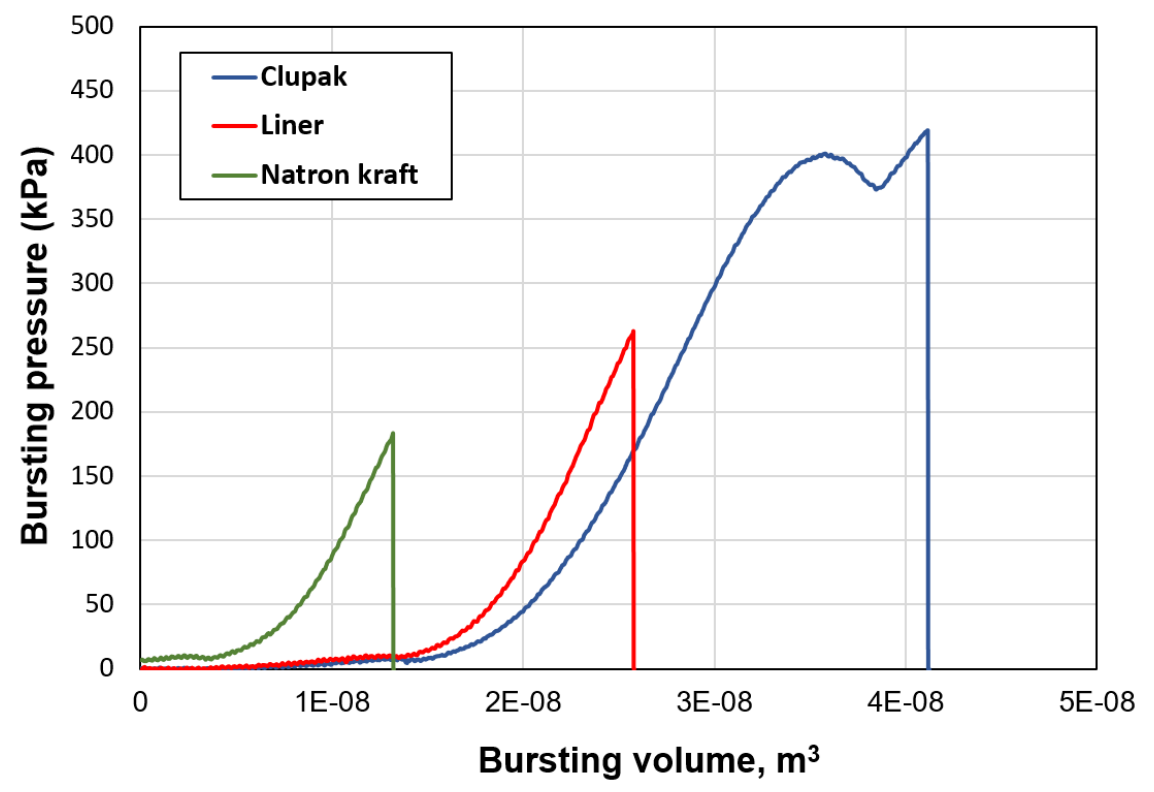

Fig. 3. Pressure as a function of the volume during a Burst test for different samples 
The maximum point represents the pressure at rupture, i.e., the bursting strength. The burst test of the Clupak specimen showed a double peak. Such characteristics is typical for certain types of paper grades. The area under the curve is the energy absorbed during the test.

The burst test has relatively low repeatability and reproducibility, resulting in testretest variability due to the heterogeneity of paper structure. This variability was confirmed during the investigation as high dispersion of the results (high STD) of the bursting strength; the coefficient of variation ranged from 6 to 14\%. Rupture usually occurred along the cross direction of paper, as the theory suggests (Fig. 1). Sometimes, however, the damage did not follow the theoretical assumptions as some edge effects influence the results (Fig. 4).

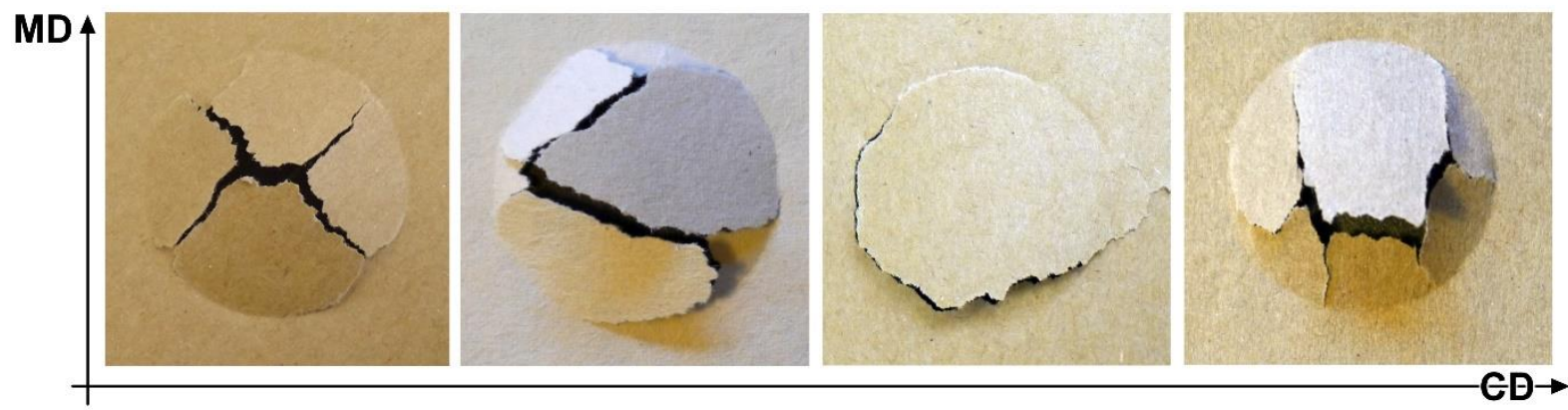

Fig. 4. Examples of the real patterns of the failure obtained during the paper bursting strength test (MD is the machine direction, $C D$ is the cross direction of each paper sample)

The comparison of the results for the BEA index $v s$. the bursting indices is presented in Fig. 5. The tests were conducted for 8 different paper grades. This figure enables a preliminary appraisal as to whether BEA index provides any additional information that could contribute to better understanding of paper strength properties. Because the BEA index is calculated from bursting pressure, a close correlation between BEA index and bursting index could be expected, regardless of the examined paper grade. In such a case, all the experimental points should lie along the same straight-line and their location should only depend on the bursting strength. This would mean that BEA does not have any significance from the viewpoint of examined material properties.

The results presented in Fig. 5 show that, for each paper grade, the correlation between BEA index and bursting strength index was linear but the proportionality differed. Despite the same bursting strength index values, some of the examined papers (e.g., Fluting and Natron, Natron and Clupak) were characterized by different bursting energy absorption indexes. The biggest differences were found for paper grades characterized by high bursting resistance (Fig. 5a). For papers with low mechanical properties (Fig. 5b), the differences, although still visible, were smaller.

Furthermore, depending on the paper grade, the slope of the linear regression curve was modified for different paper grades. This result means that there was no constant correlation between BEA and bursting strength. For some paper grades, an increase in bursting strength did not correspond to an increase in the ability to absorb the bursting energy. However, there are papers whose structure has the ability to absorb large amounts of bursting energy at a small increase in bursting strength. For instance, for Natron or Liner, an increased bursting strength did not result in an increased ability to bursting energy 
absorption. For Fluting and Clupak, however, the higher bursting strength resulted in higher bursting energy absorption. The differences in ratio between bursting strength and resulting BEA indicated that BEA and the slope of the linear regression curve contain additional information about paper behavior.
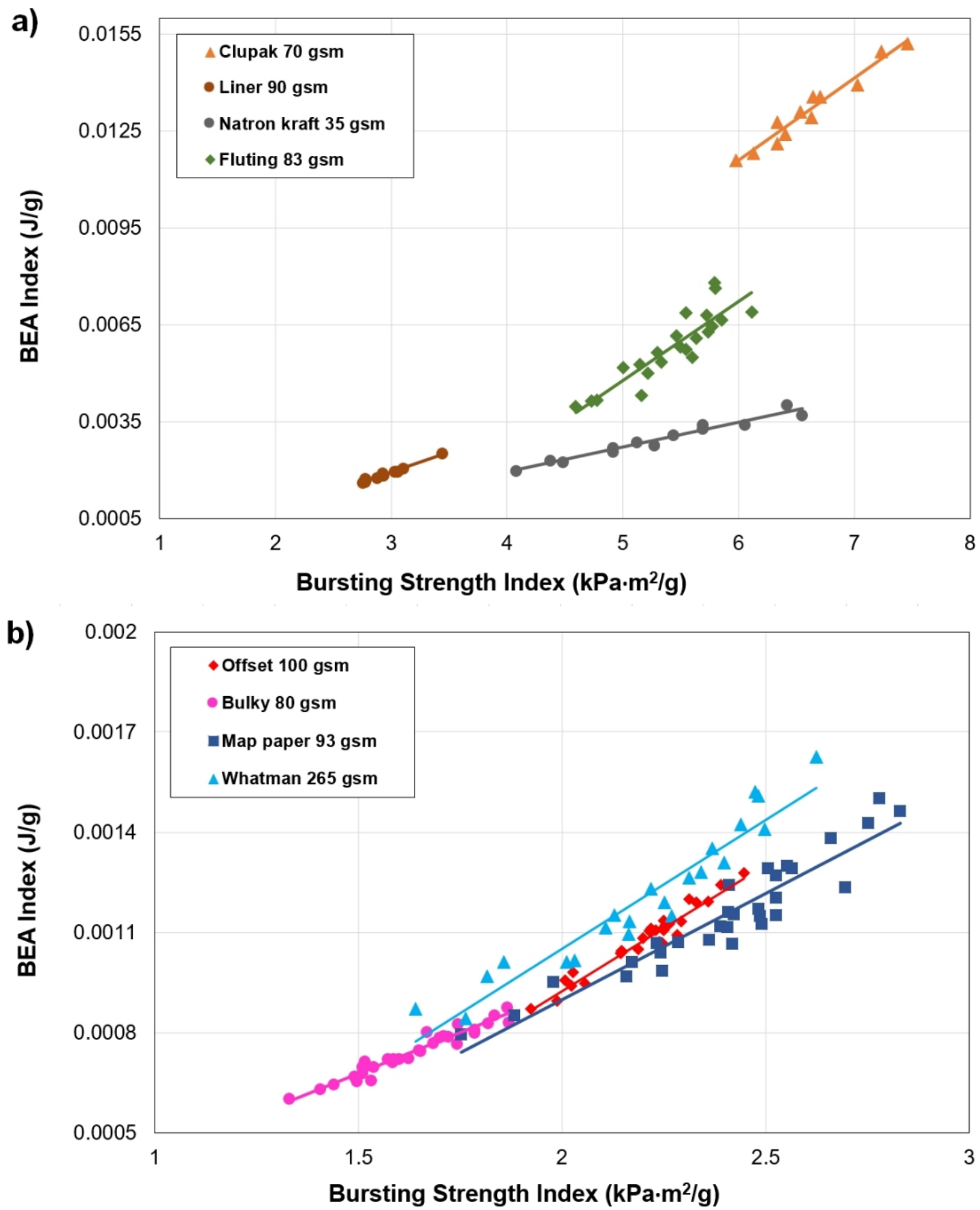

Fig. 5. Comparison of BEA Index vs. Bursting Index for different paper grades. Results obtained for: paper grades with a) high and b) low strength properties 
Based on the above considerations, the burst resistance (BR) of a given paper grade should be described by the three following parameters: average bursting strength $\left(\mathrm{P}_{\max }\right)$ or average bursting strength index (PImax), average bursting energy absorption (BEA) or average bursting energy absorption index (BEAI), and the slope $\left(\mathrm{mB}_{\mathrm{B}}\right)$ of the fitted linear regression curve (relationship between the bursting energy absorption and the bursting strength). Hence, BR can be defined by two different functions $f$ or $g$ as shown in Eq. 3 .

$$
B R=f\left(P_{\max }, B E A, m_{B}\right) \text { or } B R=g\left(P I_{\max }, B E A_{I}, m_{B}\right)
$$

Absolute values are usually more useful if one wants to know the real strength properties of the paper. Indices will be more useful when there is a need to compare different paper weights. As bursting strength largely depends on the tensile strength and extensibility of the material, it would be interesting to investigate tensile and burst acting on the same sample of paper. During these more complex deformations of paper products the additional issues were addressed:

Is BEA affected by paper stretching

a) when releasing the load just before the burst test?

b) when keeping the load during the burst test?

For this purpose, after the first preliminary investigation of a wide range of paper grades, the research focused on three types of commercial packaging papers (Natron kraft, Liner, Clupak).

\section{Influence of the Tensile Pre-Load on the Bursting Energy Absorption}

Further studies of the bursting energy absorption focused on cases where tested samples were pre-strained in CD or MD and subsequently tested in the Mullen tester ("after-load" experiments). The samples were subjected to deformation in tensile testing machine (Instron) until targeted load was obtained and subsequently tested on the modified Mullen burst tester. The results are presented in Fig. 6.

For Natron, no effect of pre-load was observed, and BEA remained almost the same for both directions (CD and MD) of pre-load. For Liner, the drop in BEA was seen for the lowest linear load and then BEA remained constant, regardless of pre-load direction. For Clupak, differences in the effect of pre-load were observed for CD and MD. For MD, if the standard deviation was taken into account, BEA remained unchanged. For CD, up to a linear pre-load of $1200 \mathrm{kN} . \mathrm{m}^{-1}$, BEA was the same as for MD pre-load. For higher preloads applied in CD, the drop in BEA was noticed. For Natron and Liner, initial instantaneous tension of the paper to the given load (both in CD and MD) had no effect on bursting energy absorption. Both papers exhibited higher elongation and lower tensile strength in CD than MD. The value of the pre-load was limited by the paper tensile strength and, therefore, the maximum pre-load in the CD was lower than in the MD. Consequently, the papers could not be tested at high values of pre-loads in CD. A noticeable decrease in BEA was observed only for Clupak pre-loaded in CD. The Clupak paper production technology is based on the use of micro-creping, which increases its extensibility in MD. For this paper, elongation was equal to $7.3 \%$ for $\mathrm{MD}$ and $7.2 \%$ for $\mathrm{CD}$, and the tensile strength was $3.94 \mathrm{kN} . \mathrm{m}^{-1}$ for MD and $2.75 \mathrm{kN} . \mathrm{m}^{-1}$ for CD. It can therefore be concluded that the elongation in MD was not a factor limiting bursting strength of Clupak. The tensile strength in $\mathrm{CD}$ was most likely the limiting factor in this case. 


\section{a) Natron kraft}
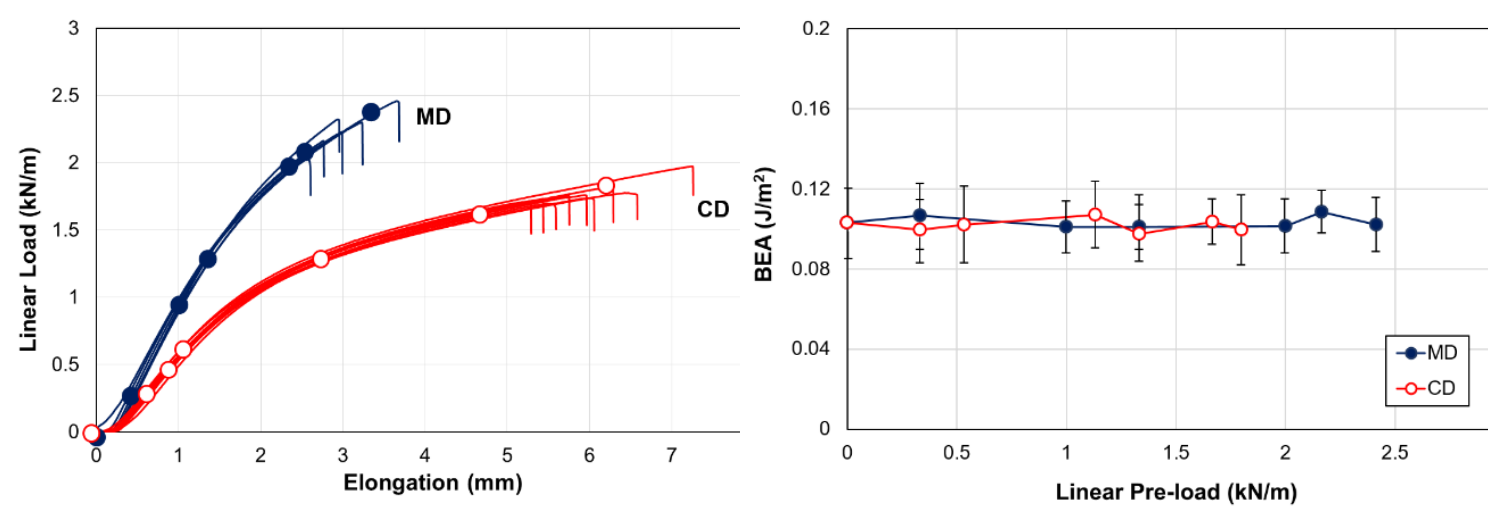

b) Liner
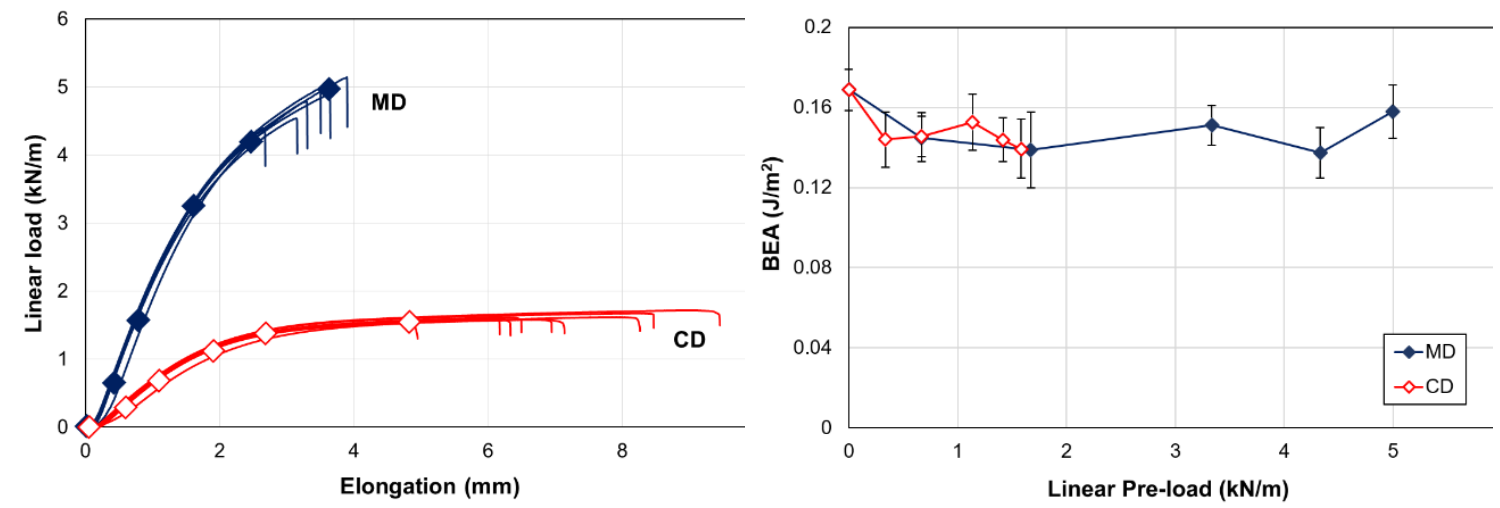

c) Clupak
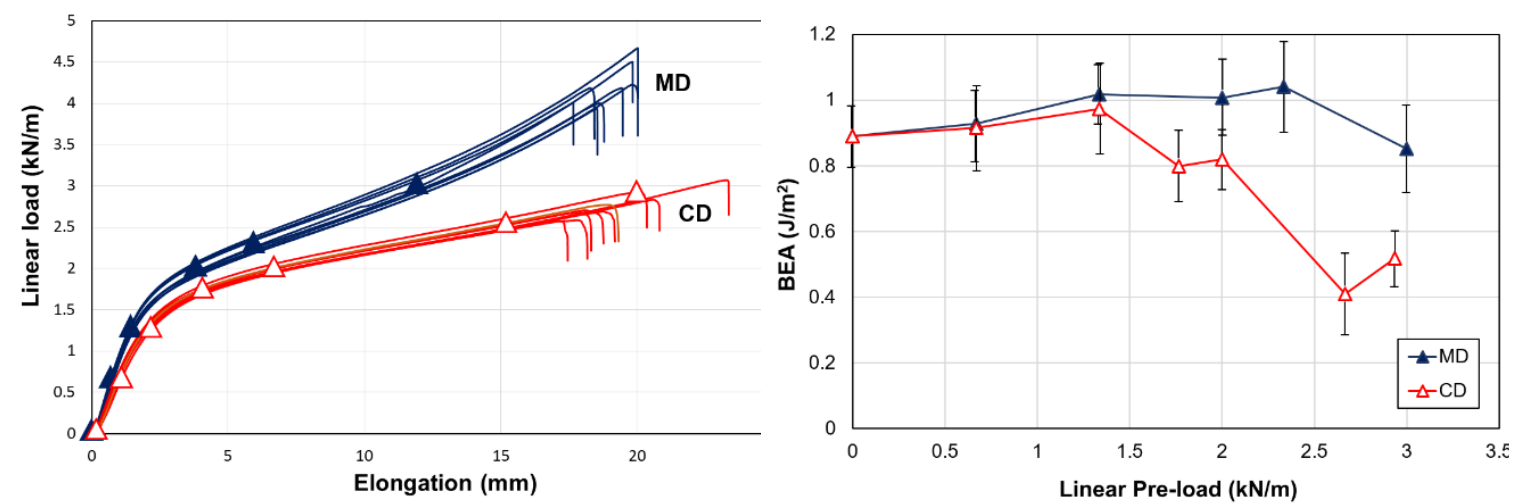

Fig. 6. Impact of pre-load (tensile test) on the bursting energy absorption for different paper grades. The tensile test are shown on the left side.

\section{Influence of the Tensile Load on the Bursting Energy Absorption}

The next stage of the research was to study the bursting energy absorption of papers that were simultaneously subjected to tensile load (in CD or MD) and tested in the Mullen tester ("under-load" experiments). The linear load applied to the sample was kept during the burst test. Figure 7 presents BEA changes induced by linear load in CD and/or MD for investigated papers. 


\section{a) Natron kraft}
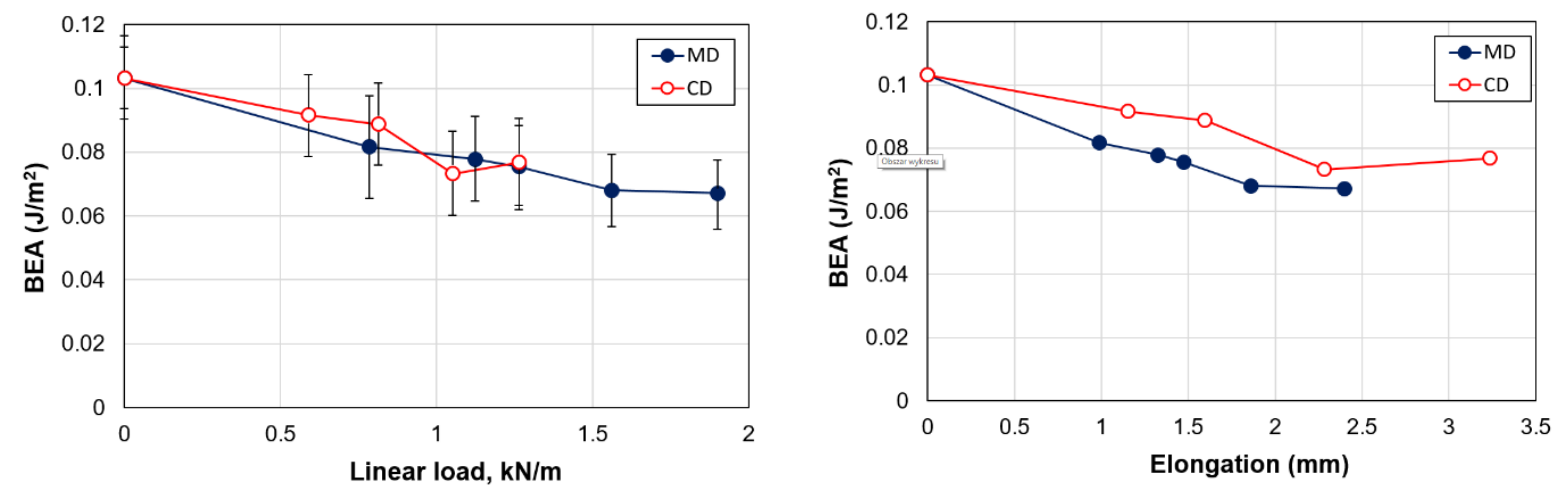

b) Liner
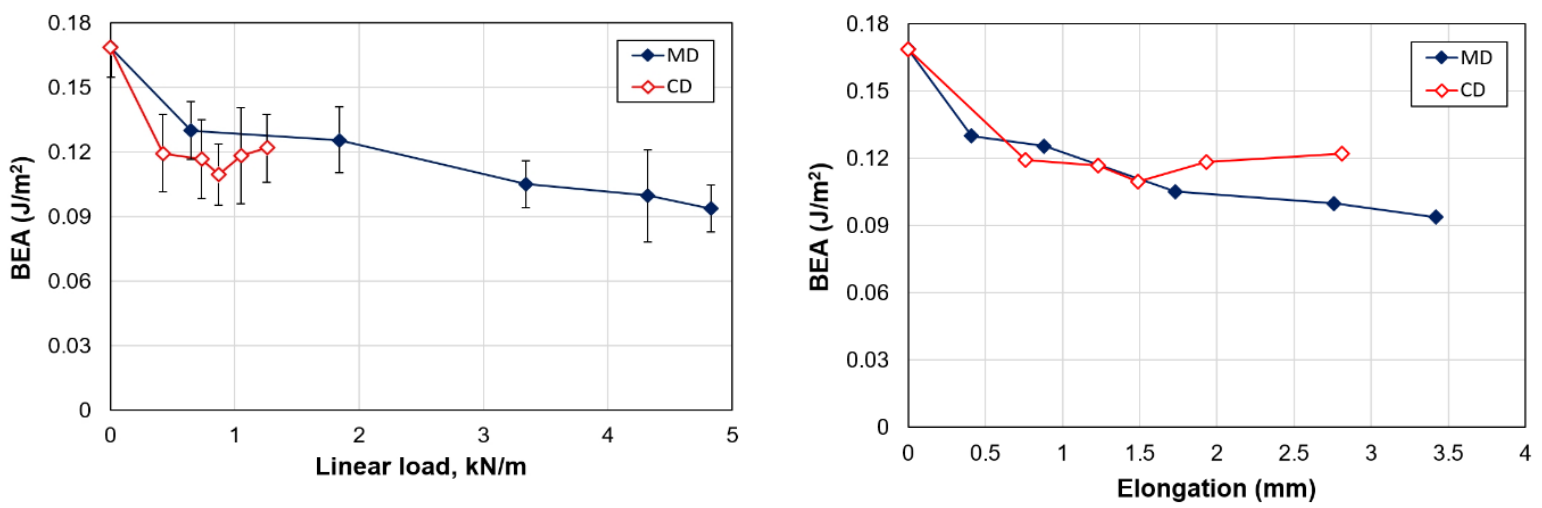

c) Clupak
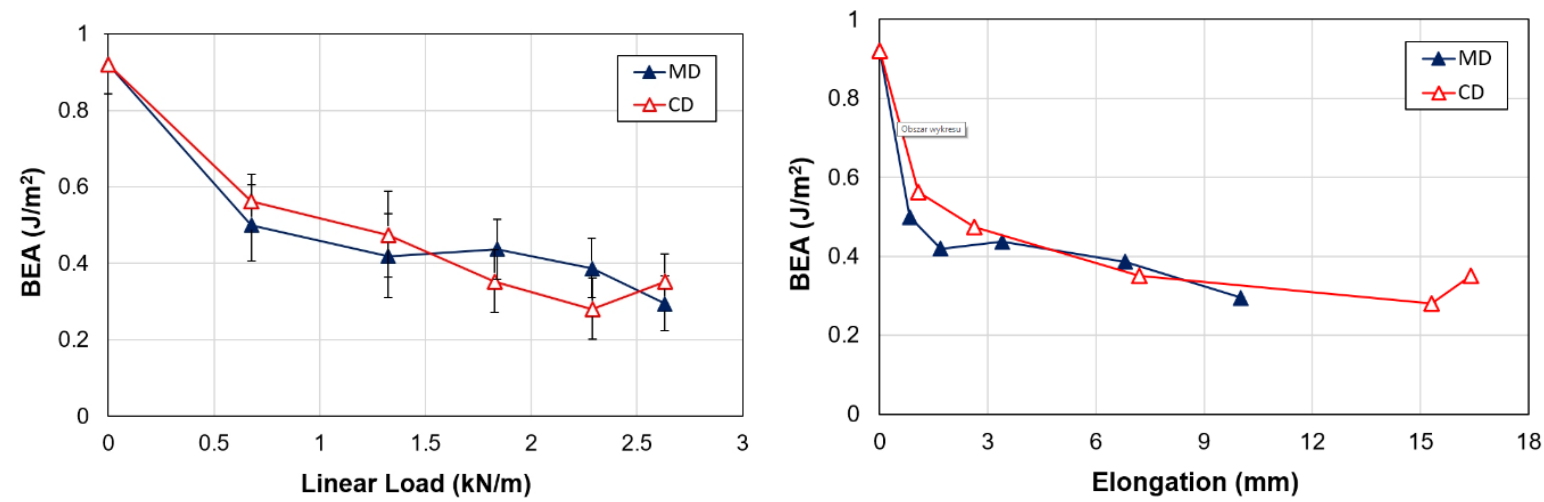

Fig. 7. Impact of the load (tensile) on the bursting energy absorption for selected paper grades (left side). On the right side BEA vs. elongation is shown.

In contrast to the after pre-load, the under-load experiments showed that BEA decreased with linear load increased. This may indicate that the stresses induced in papers by pre-load may have relaxed prior to the burst test, so none or small effect of pre-load on BEA was observed. It is worth noting that the ability of paper to absorb the bursting energy decreased with increasing elongation of the paper, which confirmed that paper structure has a limited ability to absorb energy of deformation. Deformation in any direction lowers 
the overall ability to absorb the energy that can be stored within the material. Stresses to which the paper is subjected accumulate in its structure. A paper that has been already subjected to a load will, therefore, have lower ability to absorb energy originating from the additional load.

Figure 8 presents the changes in the absorption of bursting energy as a function of the bursting pressure for the samples under different linear loads.

\section{MACHINE Direction}

\section{a) Natron kraft}

\section{CROSS Direction}
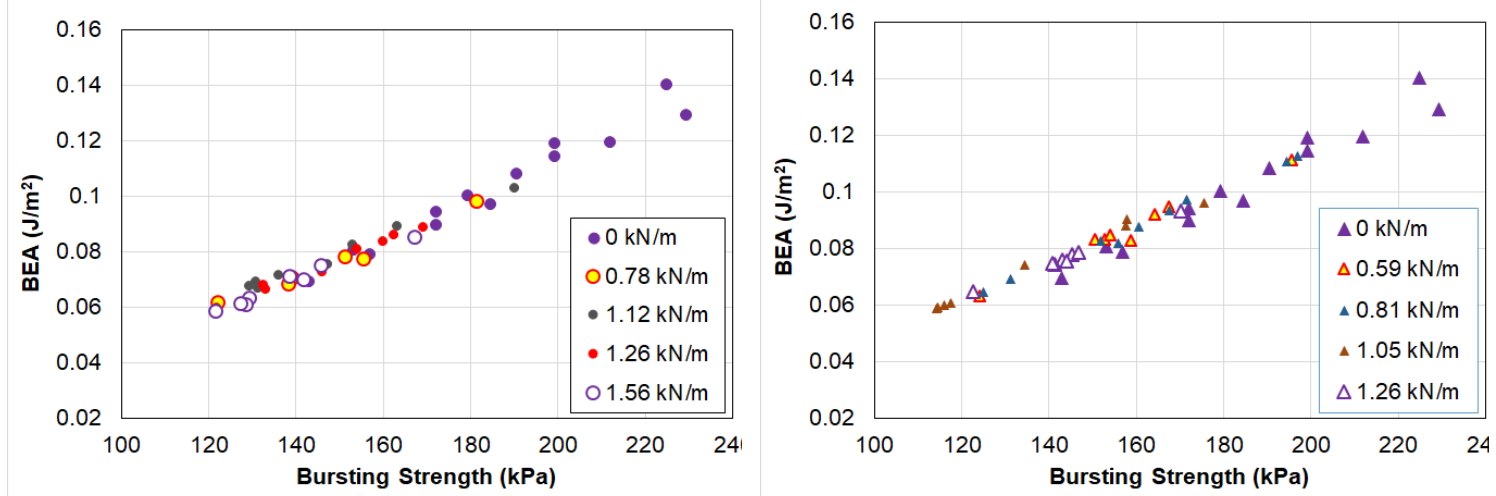

b) Liner
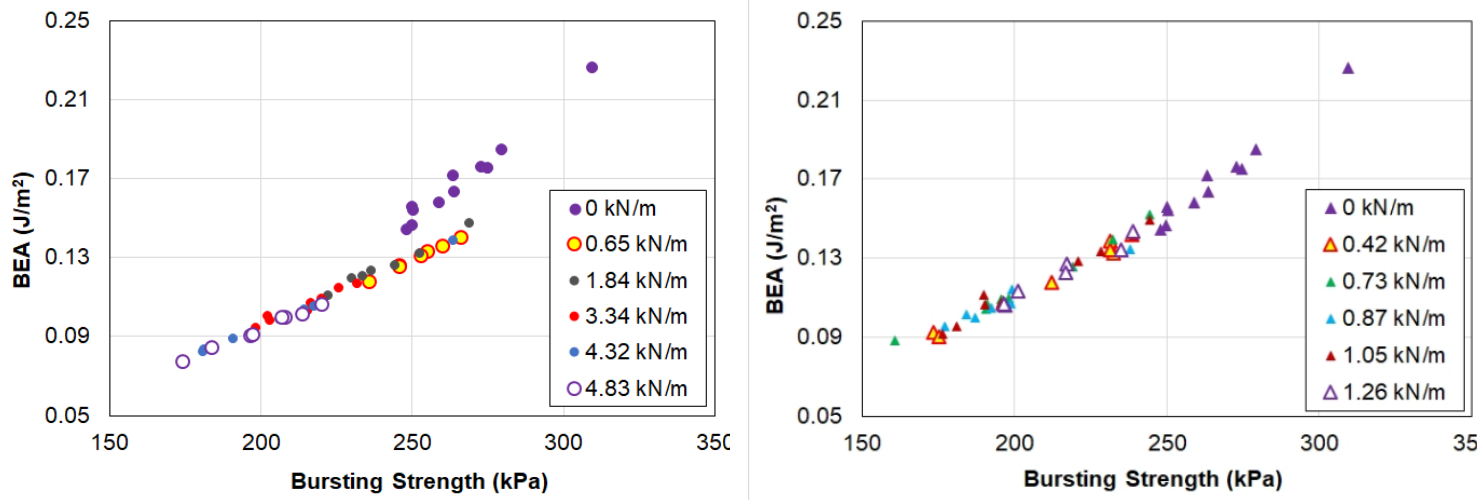

\section{c) Clupak}
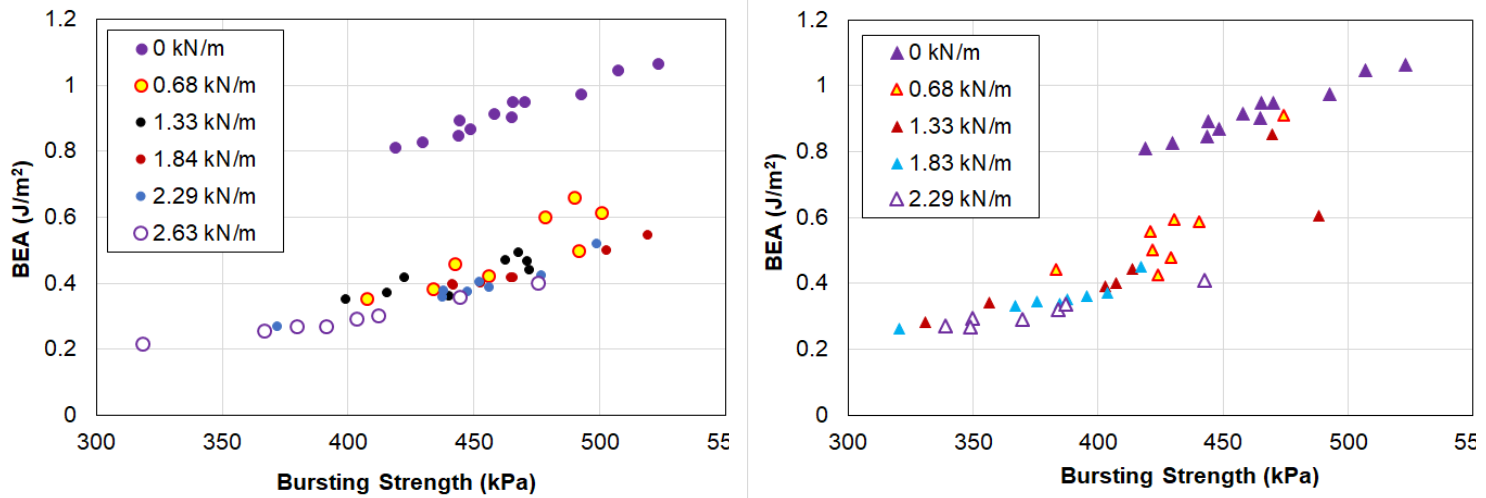

Fig. 8. Impact of the load (tensile) on the bursting energy absorption for selected paper grades in $\mathrm{MD}$ and $\mathrm{CD}$ 
Linear load was applied in the MD (plots on the left) and in the CD (plots on the right). For both the MD and $\mathrm{CD}$, additional tensile loads result in lowering of the ability of paper to absorb bursting energy. The changes were different for each examined paper. For Natron kraft paper, the ability to absorb bursting energy with increasing load was linear, and practically no differences were observed between $\mathrm{CD}$ and MD. In the case of Liner, when tensile load was applied to MD not only BEA was reduced but also the slope of the curve BEA vs. bursting pressure changed. It is interesting that such a change of slope was not observed when paper was subjected to tensile load in the CD. The highest differences in BEA were observed for Clupak. This was observed both for the MD and CD directions. In this case (Clupak), a significant reduction in bursting energy absorption occurred as well as the slope of the curve (BEA vs. bursting pressure) was changed.

Taking into account the proposed Eq. 3 describing the characteristics of the material in terms of its burst resistance, it should be noted that during the simultaneous stretching of the material in-plane and its bursting, the value of the BR parameter may differ from that for unloaded in-plane papers during bursting (e.g. Figs. 8b MD and 8c MD and CD).

Considering the description of the burst as a function of the three parameters (Eq. 3 ), Table 2 presents the results of these parameters for the two extreme cases: paper subjected to burst without tensile load and paper subjected to burst with the maximum ultimate tensile load.

Table 2. Bursting Resistance (BR) Characteristics for the Tested Paper Types

\begin{tabular}{|c|c|c|c|c|c|}
\hline Paper Grade & Load Direction & $\begin{array}{l}\text { Linear Load } \\
\left(\mathrm{kN} \cdot \mathrm{m}^{-1}\right)\end{array}$ & $P_{\max }(\mathrm{kPa})$ & $\operatorname{BEA}\left(\mathrm{J} . \mathrm{m}^{-2}\right)$ & $m_{\mathrm{B}} \cdot 10^{4}(-)$ \\
\hline \multirow{4}{*}{ Natron kraft } & \multirow{2}{*}{ MD } & 0 & 186 & 0.103 & 7.6 \\
\hline & & 1.9 & 135 & 0.067 & 6.1 \\
\hline & \multirow{2}{*}{$C D$} & 0 & 186 & 0.103 & 7.6 \\
\hline & & 1.26 & 144 & 0.077 & 6.1 \\
\hline \multirow{4}{*}{ Liner } & \multirow{2}{*}{ MD } & 0 & 266 & 0.169 & 12.4 \\
\hline & & 4.83 & 200 & 0.094 & 6.2 \\
\hline & \multirow{2}{*}{$C D$} & 0 & 266 & 0.169 & 12.4 \\
\hline & & 1.26 & 215 & 0.122 & 8.1 \\
\hline \multirow{4}{*}{ Clupak } & \multirow{2}{*}{ MD } & 0 & 464 & 0.921 & 25.5 \\
\hline & & 2.63 & 399 & 0.294 & 12.1 \\
\hline & \multirow{2}{*}{ CD } & 0 & 464 & 0.921 & 25.5 \\
\hline & & 2.63 & 382 & 0.351 & 12.9 \\
\hline
\end{tabular}

In all cases, when additional linear load was applied, all three parameters decreased. In all cases, the decline in BEA was greater in MD. For Natron and Liner, also the decrease in PMAX was greater for this direction. However, for Liner and Clupak, after applying additional linear load in the MD, a greater decrease in the $m_{\mathrm{B}}$ parameter was noted. For the Natron, the decrease in $m$ B in both directions was identical.

Changes in these parameters reveal additional differences in the mechanical properties of papers resulting from the complex nature of stress transfer in their structure.

Laboratory handsheets of isotropic fiber orientation were not used in the presented research. An interesting issue would be to investigate simultaneous stretching and bursting of papers that do not have a preferential direction of fiber orientation. These studies are in progress and will be the subject of a separate publication. 


\section{CONCLUSIONS}

1. The correlation between bursting energy absorption (BEA) and bursting strength is linear, but the proportionality is not the same. In other words, the ability of the paper to absorb the bursting energy (BEA) is not one-to-one related to its bursting strength (expressed as a maximum bursting pressure).

2. A new method has been proposed to characterize the bursting resistance (BR) of paper. Bursting resistance (BR) should be described by the three following parameters: average bursting strength $\left(P_{\max }\right)$, average bursting energy absorption (BEA), and the slope $\left(m_{\mathrm{B}}\right)$ of the fitted linear regression curve (relationship between the bursting energy absorption and the bursting strength). Appropriate indices (BEA Index, $P_{\max }$ Index) may also be used instead of absolute values.

3. The initial, temporary pre-load of the paper (in CD or MD) has no effect on the BEA. The exception was Clupak paper, which is characterized by a high extensibility. In this case, for pre-loads above $1.5 \mathrm{kN} \cdot \mathrm{m}^{-1}$ in the $\mathrm{CD}$, a decrease in the ability to absorb the bursting energy was observed. This can be explained by the fact that, in a situation where the paper exhibits similar extensibility in both directions, its resistance to bursting will most likely be limited by its CD tensile strength.

4. When the paper is simultaneously subjected to tensile forces and burst, its ability to absorb the bursting energy decreases with increasing extensibility of the paper. This finding confirms that the paper structure has a limited ability to absorb energy of deformation and that any mechanical deformation lowers its overall ability to absorb the energy.

5. The application of the proposed method of describing the bursting strength to papers subjected to simultaneous tensile load and burst revealed additional differences in the mechanical properties of investigated papers.

\section{REFERENCES CITED}

Böhmer, E. (1962). "The analogy between burst testing and conical shells," Norsk Skogindustri 16(9), 382-387.

Borch, J., Lyne M. B., Mark, R. E., and Habeger, C. (eds.) (2002). Handbook of Physical Testing of Paper: Volume 1 ( $2^{\text {nd }}$ Ed.), CRC Press, Boca Raton, FL, USA.

Carson, F. T., and Worthington, F. V. (1931). "Critical study of the bursting strength test for paper," Bureau of Standards Journal of Research 6(2), 339.

Davis, W., and Edwards C. H. (1936). "The bursting test on knitted fabrics," Journal of the Textile Institute Transactions 27(1), T13-T24, DOI: 10.1080/19447023608661666

El-Hosseiny, F., and Anderson D. (1999). "Effect of fiber length and coarseness on the burst strength of paper," Tappi Journal 82(1), 202-203.

Gander, J. W., Wachuta, J. R., and McKee, R. C. (1967). “A study of the biaxial energy absorption of sack paper. Project 2033, report forty-one: A progress report to multiwall shipping sack paper manufacturers," (https://smartech.gatech.edu/handle/1853/846), Accessed 22 May 2021.

ISO 187 (1990). "Paper, board and pulps - Standard atmosphere for conditioning and testing and procedure for monitoring the atmosphere and conditioning of samples," 
International Organization for Standardization, Geneva, Switzerland.

ISO 536 (2019). "Paper and board - Determination of grammage," International Organization for Standardization, Geneva, Switzerland.

ISO 534 (2011). "Paper and board - Determination of thickness, density and specific volume," International Organization for Standardization, Geneva, Switzerland.

ISO 1924-2 (2008). "Paper and board - Determination of tensile properties - Part 2: Constant rate of elongation method $(20 \mathrm{~mm} / \mathrm{min})$," International Organization for Standardization, Geneva, Switzerland.

ISO 2758 (2014) "Paper - Determination of bursting strength," International Organization for Standardization, Geneva, Switzerland.

ISO 2759 (2014) "Board - Determination of bursting strength," International Organization for Standardization, Geneva, Switzerland.

ISO 5626 (1993). "Paper and board - Determination of folding endurance (test method)," International Organization for Standardization, Geneva, Switzerland.

Stenitzer, F. (1967). "Bursting strength (of paper)," Das Papier 21(11), 822-828.

Strikwerda, J. C., and Considine, J. M. (1991). "Analysis of the burst test geometry-A new approach," in: International Paper Physics Conference Proceedings, Kona, HI, USA, pp. 579-584.

Szewczyk, W., and Tarnawski, W. (2004). "An analysis of the complex state of the stresses in paper as exemplified with bursting test," Fibres and Textiles in Eastern Europe 12(3), 87-90.

TAPPI T 810 om-17 (2000). "Bursting strength of corrugated board," TAPPI Press, Atlanta, GA.

TAPPI T 403 om-97 (2000). "Bursting strength of paper," TAPPI Press, Atlanta, GA. Whitsitt, W. J. (1972a). "Theory, use and calibration of bursting strength testers. Part 1," Boxboard Containers 80(1), 34-36

Whitsitt, W. J. (1972b). "Theory, use and calibration of bursting strength testers. Part 2," Boxboard Containers 80(2), 53-57

Whitsitt, W. J. (1972c). "Theory, use and calibration of bursting strength testers. Part 3," Boxboard Containers 80(3), 50-56

Article submitted: July 4, 2021; Peer review completed: August 10, 2021; Revised version received and accepted: September 9, 2021; Published: September 10, 2021. DOI: 10.15376/biores.16.4.7249-7262 